\title{
Efeito de Herbicidas na Atividade Microbiana do Solo ${ }^{1}$
}

\author{
Effect of Herbicides on Soil Microbial Activity
}

\author{
TIRONI, S.P. ${ }^{2}$, BELO, A.F..$^{2}$, FIALHO, C.M.T. ${ }^{2}$, GALON, L. ${ }^{2}$, FERREIRA, E.A. ${ }^{2}$, SILVA, A.A. ${ }^{3}$, \\ COSTA, M.D. ${ }^{4}$ e BARBOSA, M.H.P. ${ }^{3}$
}

\begin{abstract}
RESUMO - Objetivou-se com este trabalho avaliar os efeitos de herbicidas e doses na atividade microbiana e no potencial de solubilização de fosfato inorgânico de solo cultivado com cana-de-açúcar. Os tratamentos foram constituídos pelos herbicidas ametryn, trifloxysulfuron-sodium e pela mistura (ametryn + trifloxysulfuron-sodium), aplicados nas doses de 0, 1, 2, 4 e 8 vezes a dose-referência de 10, 0,112 e 7,315 + 0,185 $\mathrm{mg} \mathrm{dm}^{-3} \mathrm{do}$ ingrediente ativo dos respectivos herbicidas. Após aplicação dos tratamentos, as amostras de solo foram incubadas por 15 dias, realizando-se as avaliações da evolução de $\mathrm{CO}_{2}$ do solo $\left(\mathrm{C}-\mathrm{CO}_{2}\right)$ em intervalos de três dias. Ao final do periodo de incubação foram realizadas análises de carbono da biomassa microbiana $(\mathrm{CBM})$, quociente metabólico $\left(\mathrm{qCO}_{2}\right)$, potencial de solubilização e solubilização relativa de fosfato inorgânico do solo. A evolução de $\mathrm{C}-\mathrm{CO}_{2}$ foi influenciada pelas maiores doses dos herbicidas, sendo reduzida com a aplicação do trifloxysulfuron-sodium $(10,31 \%)$ e elevada com os demais herbicidas, com maiores efeitos logo após a aplicação. $\mathrm{O} \mathrm{CBM}$ e $\mathrm{O} \mathrm{qCO}_{2}$ foram influenciados negativamente pelos herbicidas ametryn e trifloxysulfuron-sodium + ametryn, com maiores efeitos quanto maiores as doses. $\mathrm{O}$ trifloxysulfuron-sodium provocou a redução do $\mathrm{CBM}$ nas menores doses e incremento deste nas maiores, promovendo a redução do $\mathrm{qCO}_{2}$. A solubilização potencial de fosfato inorgânico decresceu com a aplicação do ametryn $(47,20 \%)$ e da mistura $(13,55 \%)$, sendo estimulada pelo trifloxysulfuron-sodium $(25,48 \%)$. O potencial de solubilização relativa teve comportamento semelhante.
\end{abstract}

Palavras-chave: biomassa microbiana, solubilização de fosfato, ametryn, trifloxysulfuron-sodium.

\begin{abstract}
This work aimed to evaluate the effects of herbicides and doses on the microbial activity and inorganic phosphate solubilization potential of a soil cultivated with sugarcane. The treatments were composed by the herbicides ametryn, trifloxysulfuron-sodium, and ametryn + trifloxysulfuron-sodium at $0,1,2,4$, and 8 times the reference doses of 10, 0.112, and 7.315+ $0.185 \mathrm{mg} \mathrm{dm^{3 }}$ of the active ingredient, respectively. After herbicide application, soil samples were incubated for 15 days and $\mathrm{CO}_{2}$ evolution $\left(\mathrm{C}-\mathrm{CO}_{2}\right)$ was evaluated every three days. At the end of incubation, microbial biomass carbon (MBC), metabolic quotient (qCO2), phosphate solubilization potential, and relative phosphate solubilization were evaluated for the treatments tested. $C-\mathrm{CO}_{2}$ evolution was affected by the herbicides and increasing application doses. Trifloxysulfuron-sodium caused a reduction in $\mathrm{C}-\mathrm{CO}_{2}$ evolution of $10.3 \%$ in comparison to the control. $\mathrm{MBC}$ and $q \mathrm{CO}_{2}$ were negatively affected by the herbicides ametryn and trifloxysulfuron-sodium + ametryn. Trifloxysulfuron-sodium reduced $M B C$ when applied at decreasing doses; the reverse was observed for $\mathrm{qCO}_{2}$. Phosphate solubilization potential was reduced with the application of ametryn (47.20\%) and trifloxysulfuron-sodium + ametryn (13.55\%), while trifloxysulfuron-sodium applied singly stimulated this activity in the soil (25.48\%). Similar behavior was observed for relative phosphate solubilization.
\end{abstract}

Keywords: microbial biomass, phosphate solubilization, ametryn, trifloxysulfuron-sodium.

1 Recebido para publicação em 12.4.2009 e na forma revisada em 11.12.2009.

2 Engô-Agrọ , aluno do Programa de Pós-Graduação em Fitotecnia da Universidade Federal de Viçosa - DEF/UFV,

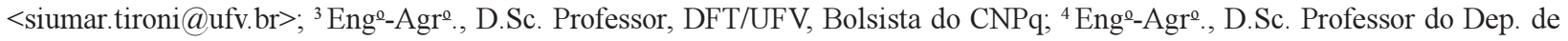
Microbiologia - DBM/UFV.

Planta Daninha, Viçosa-MG, v. 27, p. 995-1004, 2009. Número Especial 


\section{INTRODUÇÃO}

No Brasil, a área cultivada com cana-deaçúcar vem se expandindo rapidamente nos últimos anos, com perspectivas de maior crescimento nas próximas safras (IBGE, 2008). A produção da cana-de-açúcar está sendo estimulada principalmente para suprir a crescente demanda de etanol, usado como combustivel. Essa cultura é de grande importância para a economia brasileira, tendo em vista que é a mais utilizada para a produção de açúcar e álcool (Christoffoleti et al., 2006).

O aumento da demanda de álcool leva à necessidade de se elevar a produtividade da cana-de-açúcar. No entanto, existem alguns fatores limitantes, a exemplo da baixa fertilidade do solo (Reis Jr. \& Monnerat, 2002) e da interferência causada pelas plantas daninhas, que podem frustrar os esforços para o aumento da produtividade (Kuva et al., 2003). Entre os nutrientes limitantes da produtividade de cana-de-açúcar, destacam-se o potássio (K), fósforo $(\mathrm{P})$ e enxofre (S) (Reis Jr. \& Monnerat, 2002). As plantas daninhas competem com a cultura pelos recursos escassos do meio, inclusive por nutrientes, causando perdas expressivas na produtividade, na qualidade do produto colhido e também na longevidade do canavial (Kuva et al., 2003; Negrisoli et al., 2004).

A dinâmica dos nutrientes no solo é influenciada pela atividade microbiana, que promove a decomposição da matéria orgânica (mineralização) e solubilização de nutrientes contidos na fase sólida do solo, com destaque para o P (Tótola \& Chaer, 2002; Bottomley, 2005). Esses microrganismos também desempenham outras funções importantes, como a supressão de patógenos, a produção de fitormônios e a decomposição de compostos xenobióticos, entre eles os agrotóxicos (Bottomley, 2005).

A utilização de agrotóxicos, em especial os herbicidas, pode influenciar a dinâmica dos microrganismos do solo (Santos et al., 2005; Jakelaitis et al., 2007; Reis et al., 2008a), podendo apresentar efeitos maléficos, benéfi$\cos$ (Reis et al., 2008b) ou nulos (Pereira et al., 2008). Entre os indicadores do impacto de produtos xenobióticos sobre os microrganismos de solo, os mais comuns são: a evolução de
$\mathrm{CO}_{2}$ do solo $\left(\mathrm{C}-\mathrm{CO}_{2}\right)$, o carbono da biomassa microbiana $(\mathrm{CBM})$, o quociente metabólico $\left(\mathrm{qCO}_{2}\right)($ Brookes, 1995) e o potencial de solubilização de fosfato inorgânico, usado como indicador da dinâmica do P no solo (Leita et al., 1995). A biomassa microbiana do solo é a fração viva da matéria orgânica, responsável por processos bioquímicos e biológicos (Moreira \& Siqueira, 2003), encontrada em maior concentração no solo rizosférico, em função do maior aporte de carbono orgânico facilmente assimilável, exsudado pelo sistema radicular das plantas (Nautiyal, 1999). O $\mathrm{qCO}_{2}$ representa a respiração por unidade de biomassa, em que os maiores valores são atribuídos a condições estressantes aos microrganismos, e os menores, à maior eficiência destes na incorporação de carbono à biomassa (Sakamoto \& Obo, 1994).

Os microrganismos solubilizadores de fosfato inorgânico (MSFI) são considerados indicadores de impactos ao ambiente e importantes para a produção agrícola. Os MSFI têm maior importância em solos tropicais, os quais apresentam grande quantidade de $\mathrm{P}$ complexado com óxidos de ferro $(\mathrm{Fe})$ e aluminio (A1) (Novais \& Smyth, 1999). Alguns trabalhos demonstram a importância dos MSFI encontrados no solo rizosférico no suprimento de $\mathrm{P}$ e, consequentemente, na promoção de crescimento das plantas (Freitas et al., 1997; Gyaneshwar et al., 2002), em decorrência da interação com as plantas. Entretanto, vários fatores influenciam a atividade dos microrganismos do solo e a solubilização de fosfato inorgânico, como a fonte de carbono e nitrogênio disponiveis (Nautiyal et al., 2000), a espécie de planta cultivada (Grayston et al. 1996), a fonte de fosfato (Barroso \& Nahas, 2005) e a presença de agrotóxicos (inseticidas, fungicidas e herbicidas) (Das, 2003; Reis et al., 2008a).

O manejo do solo pode interferir na qualidade deste, comprometendo a estabilidade e a sustentabilidade do sistema (Franzluebbers, 2007). Todavia, a maioria das características físico-químicas do solo são pouco alteradas pelo sistema de manejo adotado em curto período de tempo. Os indicadores mais responsivos no curto prazo são os critérios bioquímicos e microbiológicos em razão da maior sensibilidade às perturbações (Chaer \& Tótola, 2007) - estes 
de grande importância para o sistema agrícola. Souza et al. (2008), ao investigarem os indicadores da qualidade do solo em relação à intensidade de pastejo, não observaram redução do carbono total do solo, porém verificaram alterações no carbono e no $\mathrm{P}$ da biomassa microbiana. Reis et al. (2008a) observaram estímulo de solubilização de fosfato inorgânico do solo rizosférico de cana-de-açúcar cultivada em ambiente protegido ao aplicarem o trifloxysulfuron-sodium sobre a cultura. Entretanto, Vivian et al. (2006) e Reis et al. (2008b) verificaram que outros herbicidas utilizados na cultura influenciaram negativamente o $\mathrm{CBM}$, o $\mathrm{qCO}_{2}$ e outros indicadores microbiológicos da qualidade do solo na canade-açúcar.

O método de manejo das plantas daninhas mais utilizado em lavouras de cana-de-açúcar é o químico, com o uso de herbicidas (Christofoletti, 2006). Para essa cultura, são utilizados herbicidas de alta persistência no solo, para controlar o estabelecimento das plantas daninhas por longo período de tempo, em razão de o período crítico de controle das plantas daninhas da cultura ser longo, variando de 50 a 130 dias após a emergência (Procópio et al., 2003; Kuva et al., 2003). Dos herbicidas utilizados na cultura da cana-de-açúcar, destacam-se o ametryn e o trifloxysulfuronsodium, classificados respectivamente como muito tóxico e tóxico para o ambiente (Agrofit, 2008). Esses herbicidas podem ser aplicados isoladamente ou em mistura comercial, aumentando assim o espectro de controle (Syngenta, 2006).

Objetivou-se com este trabalho avaliar o efeito de doses dos herbicidas ametryn, trifloxysulfuron-sodium e trifloxysulfuronsodium + ametryn sobre a evolução de $\mathrm{CO}_{2}$ do solo $\left(\mathrm{C}-\mathrm{CO}_{2}\right)$, carbono da biomassa microbiana $(\mathrm{CBM})$, quociente metabólico $\left(\mathrm{qCO}_{2}\right)$ e no potencial de solubilização de fosfato inorgânico de solo cultivado com cana-de-açúcar.

\section{MATERIAL E MÉTODOS}

O experimento foi conduzido no Laboratório de Herbicida no Solo do Departamento de Fitotecnia e no Laboratório de Associações Micorrizicas do Departamento de Microbiologia/ BIOAGRO, ambos da Universidade Federal de Viçosa (UFV), Viçosa-MG. Amostras de solo foram coletados em área cultivada com canade-açúcar na Estação Experimental da Horta Nova, pertencente à UFV, no município de Viçosa-MG. As amostras de solo coletadas foram peneiradas (malha de $2 \mathrm{~mm}$ ) e armazenadas a $4^{\circ} \mathrm{C}$ por um dia, sendo realizada a análise de equivalente umidade e das características físicas e químicas (Tabela 1). A seguir, amostras de $100 \mathrm{~g}$ de solo a $60 \%$ da capacidade de campo foram acondicionadas em frascos, realizando-se a aplicação dos tratamentos, seguida da incubação por 15 dias a $22{ }^{\circ} \mathrm{C}( \pm 2)$. O experimento foi realizado em delineamento experimental inteiramente casualizado, com quatro repetições. Cada frasco correspondeu a uma unidade experimental. Os tratamentos foram constituídos de um esquema fatorial ( $3 \times 5$ ), sendo o fator A constituído pelos herbicidas formulados Metrimex $500 \mathrm{SC}^{\circledR}$ (ametryn - $10 \mathrm{mg} \mathrm{dm}{ }^{-3}$ ), Envoke ${ }^{\circledR}$ (trifloxysulfuron-sodium - 0,112 $\mathrm{mg} \mathrm{dm}^{-3}$ ) e Krismat ${ }^{\circledR}$ (ametryn + trifloxysulfuron-sodium $7,315+0,185 \mathrm{mg} \mathrm{dm}^{-3}$ ), e o fator B, pelas doses

Tabela 1 - Características químicas do solo, de amostras coletadas de 0 a 10 cm em lavouras de cana-de-açúcar. Viçosa-MG, 2008

\begin{tabular}{|c|c|c|c|c|c|c|c|c|c|c|c|c|}
\hline \multicolumn{13}{|c|}{ Características químicas $^{1 /}$} \\
\hline $\mathrm{pH}$ & $\mathrm{P}$ & $\mathrm{K}^{+}$ & $\mathrm{Ca}^{2+}$ & $\mathrm{Mg}^{2+}$ & $\mathrm{Al}^{3+}$ & $\mathrm{H}+\mathrm{Al}$ & SB & $\mathrm{CTC}(\mathrm{t})$ & CTC (T) & $\mathrm{V}$ & $\mathrm{m}$ & $\mathrm{MO}$ \\
\hline$\left(\mathrm{H}_{2} \mathrm{O}\right)$ & \multicolumn{2}{|c|}{$\left(\mathrm{mg} \mathrm{dm}^{-3}\right)$} & \multicolumn{7}{|c|}{$\left(\mathrm{cmol}_{\mathrm{c}} \mathrm{dm}^{-3}\right)$} & \multicolumn{2}{|c|}{$\%$} & $\left(\right.$ dag kg $\left.{ }^{-1}\right)$ \\
\hline 6,0 & 7,4 & 168 & 4,2 & 0,7 & 0,0 & 4,46 & 5,33 & 5,33 & 9,79 & 54 & 0 & 2,4 \\
\hline \multicolumn{13}{|c|}{ Características físicas $^{1 /}$} \\
\hline & & & Silte & & grossa & & Fina & \multirow{2}{*}{\multicolumn{5}{|c|}{ Classificação textural }} \\
\hline \multicolumn{8}{|c|}{$(\%)$} & & & & & \\
\hline & & & 32 & & 7 & & 4 & \multicolumn{5}{|c|}{ Argiloso } \\
\hline
\end{tabular}

1/ Análise realizada no Laboratório de Análise de Solos Viçosa Ltda; CTC (T): capacidade da troca de cátions (pH 7); CTC (t): capacidade de troca de cátions efetiva; V: saturação de bases; m: saturação de alumínio; MO: matéria orgânica. 
de $0,1,2,4$ e 8 vezes a dose-referência de cada herbicida (proporcional à recomendada).

$\mathrm{Na}$ avaliação da taxa respiratória utilizou-se o método respirométrico de avaliação do $\mathrm{C}-\mathrm{CO}_{2}$ evoluído do solo. As amostras foram incubadas durante 15 dias em frascos hermeticamente fechados. $\mathrm{O} \mathrm{C}-\mathrm{CO}_{2}$ liberado do solo foi carreado por fluxo contínuo de ar (isento de $\mathrm{CO}_{2}$ ) até um tubo contendo $30 \mathrm{~mL}$ de solução de $\mathrm{NaOH}$ 0,25 $\mathrm{mol} \mathrm{L}^{-1}$. Em intervalos de três dias, estimou-se o C- $\mathrm{CO}_{2}$ evoluído a partir da titulação de $10 \mathrm{~mL}$ da solução de $\mathrm{NaOH}$ com solução de $\mathrm{HCl} 0,1 \mathrm{~mol} \mathrm{~L}^{-1}$, preenchendo-se novamente os tubos com $30 \mathrm{~mL}$ de solução de

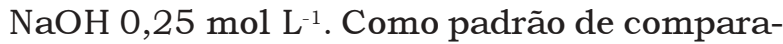
ção, indicando a qualidade do ar, utilizaram-se frascos sem solo, chamado de amostra "em branco", em relação às demais.

Após o período de incubação, foi feita a análise do carbono da biomassa microbiana (CMB), seguindo o método descrito por Vance et al. (1987), modificado por Islam \& Weil (1998). Foram retiradas duas porções de solo de cada tratamento (18 g), sendo uma submetida à radiação de micro-ondas por tempo previamente calculado $(60 \mathrm{~s}+60 \mathrm{~s})$, substituindo a fumigação com clorofórmio. Foram adicionados às amostras de solo $80 \mathrm{~mL}$ de $\mathrm{K}_{2} \mathrm{SO}_{4}$ 0,5 $\mathrm{mol} \mathrm{L}^{-1}$. Em seguida, as amostras foram agitadas por 30 minutos em mesa agitadora horizontal, permanecendo em repouso por mais 30 minutos, para decantação. Posteriormente, a fase superior foi filtrada em papel-filtro Whatman $n^{\circ} 42$. Foram adicionados $10 \mathrm{~mL}$ do filtrado em tubos digestores e a seguir adicionados os reagentes: $2 \mathrm{~mL}$ de solução $\mathrm{K}_{2} \mathrm{Cr}_{2} \mathrm{O}_{7} 0,0667 \mathrm{~mol} \mathrm{~L}^{-1}$; e $10 \mathrm{~mL}$ de $\mathrm{H}_{2} \mathrm{SO}_{4}$ concentrado. Após o resfriamento, a solução foi completada para $100 \mathrm{~mL}$ com água destilada e adicionado o indicador de difenilamina (seis gotas), procedendo em seguida à titulação com solução $0,333 \mathrm{~mol} \mathrm{~L}^{-1}$ de $\left(\mathrm{NH}_{4}\right)_{2} \mathrm{Fe}\left(\mathrm{SO}_{4}\right)_{2}$ até a mudança de coloração para vermelho-tijolo. O CBM foi estimado pela diferença entre a amostra irradiada e a não irradiada. Com a relação entre os valores de $\mathrm{C}-\mathrm{CO}_{2}$ e CBM, determinou-se o quociente metabólico $\left(\mathrm{qCO}_{2}\right)$, que representa a quantidade de evolução de $\mathrm{CO}_{2}$ diário por unidade de biomassa.

Após o período de incubação, determinouse o potencial de solubilização de fosfato inorgânico pelos microrganismos do solo, em meio líquido. Para isso, transferiu-se $1 \mathrm{~g}$ de solo, de cada tratamento, para tubo de ensaio com meio líquido NBRI, pH 6,8-7,0, contendo ( $\mathrm{g} \mathrm{L}^{-1}$ ): glicose, 10; $\mathrm{Ca}_{3}\left(\mathrm{PO}_{4}\right)_{2}, 5 ; \mathrm{MgCl}_{2} \cdot 6 \mathrm{H}_{2} \mathrm{O}, 0,5$; $\mathrm{MgSO}_{4} \cdot 7 \mathrm{H}_{2} \mathrm{O}, 0,25 ; \mathrm{KCl}, 0,2$; e $\left(\mathrm{NH}_{4}\right)_{2} \mathrm{SO}_{4}, 0,1$ (Nautiyal, 1999). Após incubação por 15 dias a $30^{\circ} \mathrm{C}, 1,5 \mathrm{~mL}$ da fase liquida foi submetido à centrifugação (8.000 rpm por 20 minutos). Em seguida, determinou-se a quantidade de $\mathrm{P}$ inorgânico do sobrenadante pelo método colorimétrico da vitamina $C$ modificada, a $725 \mathrm{~nm}$ (Braga \& Defelipo, 1974).

Os dados foram submetidos à análise de variância e, posteriormente, realizaram-se análises de regressão. A escolha dos modelos baseou-se na significância estatística $(F)$, no coeficiente de determinação $\left(R^{2}\right)$ e na explicação dos fenômenos biológicos. As equações ajustadas foram comparadas pelo teste de identidade dos modelos, tanto para os modelos lineares (Regazzi, 1993) quanto para os não lineares (Regazzi \& Silva, 2004). Todas as avaliações foram efetuadas a $5 \%$ de probabilidade.

\section{RESULTADOS E DISCUSSÃO}

A evolução diária de $\mathrm{C}-\mathrm{CO}_{2}$ do solo em função das doses de trifloxysulfuron-sodium apresentou maiores valores logo após a sua aplicação, decrescendo ao longo do tempo (Figura 1A). Somente o tratamento com a maior dose do trifloxysulfuron-sodium diferenciou-se dos demais quanto ao $\mathrm{C}-\mathrm{CO}_{2}$, esses representados por uma taxa respiratória comum (Figura 1A). A menor evolução de $\mathrm{C}-\mathrm{CO}_{2}$ pode ser indicativo de maior eficiência no uso dos recursos do solo (Sakamoto \& Obo, 1994), desde que se mantenha a mesma biomassa microbiana. Contudo, pode também ocorrer devido à redução da população microbiana, em função de a toxicidade do composto reduzir a evolução de $\mathrm{C}-\mathrm{CO}_{2}$, o que não é denotado nas menores doses, pela baixa dose aplicada do herbicida. Zabaloy et al. (2008) observaram que o metsulfuron-methyl (inibidor da enzima ALS), aplicado em dez vezes a dose recomendada, não alterou o $\mathrm{C}-\mathrm{CO}_{2}$ do solo.

$\mathrm{O}$ trifloxysulfuron-sodium proporcionou menor taxa na evolução acumulada de $\mathrm{CO}_{2}$ na maior dose testada (oito vezes). Os demais tratamentos com herbicida diferiram da 


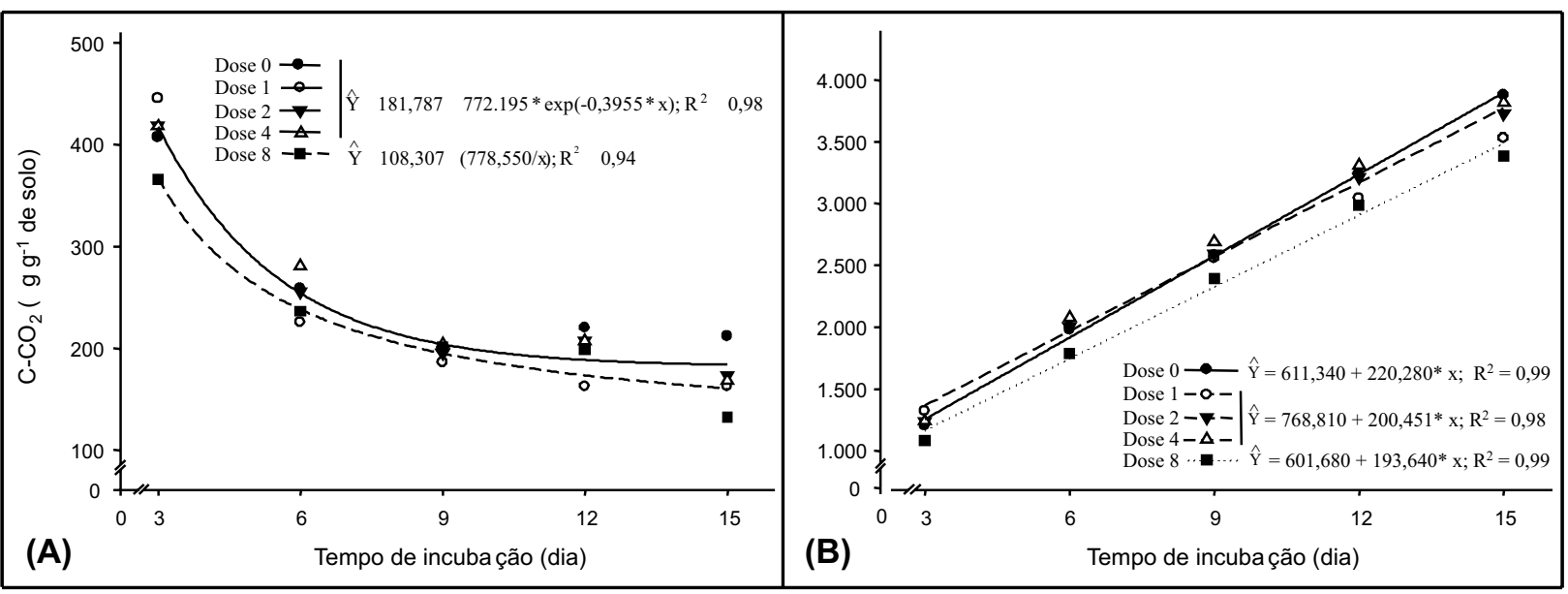

Figura 1 - Evolução diária (A) e acumulada (B) de $\mathrm{CO}_{2}\left(\mathrm{C}-\mathrm{CO}_{2}\right)$ do solo após a incubação em função, da aplicação do

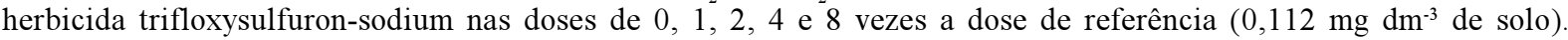
Viçosa-MG, 2008.

testemunha e não entre si, apresentando logo após a aplicação maiores taxas respiratórias e menores ao final do período de incubação. Reis et al. (2008a) observaram, ao aplicarem o trifloxysulfuron-sodium sobre cana-deaçúcar cultivada em casa de vegetação, que esse produto estimulou a evolução de $\mathrm{C}-\mathrm{CO}_{2}$ do solo rizosférico. Alguns autores atribuem a maior evolução de $\mathrm{C}-\mathrm{CO}_{2}$ dos solos tratados com herbicidas ao fato de este servir como fonte de carbono e energia aos microrganismos (Costa et al., 1997; Moreno, 2007). No entanto, isso é pouco provável para o trifloxysulfuronsodium, devido à baixa quantidade utilizada por área.

$\mathrm{O}$ ametryn provocou incremento da evolução de $\mathrm{C}-\mathrm{CO}_{2}$ diária do solo somente na maior dose aplicada (Figura 2A), com maiores evoluções de $\mathrm{CO}_{2}$ logo após a aplicação. O composto pode ter sido tóxico para parte da comunidade microbiana, reduzindo a população ao longo do tempo e, consequentemente, diminuindo a evolução de $\mathrm{C}-\mathrm{CO}_{2}$ total do solo. Resultados semelhantes a estes foram observados por Santos et al. (2005), após a aplicação de doses do herbicida fomesafen em plantas de feijão.

A evolução de $\mathrm{C}-\mathrm{CO}_{2}$ acumulada do solo em função das doses de ametryn foi maior quando se utilizou duas vezes a dose de referência (10 $\mathrm{mg} \mathrm{dm}^{-3}$ de solo). A menor taxa de evolução de $\mathrm{C}-\mathrm{CO}_{2}$ foi observada no tratamento sem aplicação de herbicidas. Os demais tratamentos apresentaram respiração intermediária, sendo representados por uma única equação (Figura 2B). Alterações na taxa de evolução de $\mathrm{C}-\mathrm{CO}_{2}$ do solo podem ser atribuída aos efeitos tóxicos do herbicida, como relatado anteriormente. Não foi observada diferença entre os tratamentos que receberam quatro, oito e uma vez a dose do ametryn. Isso pode ser explicado pela maior taxa respiratória por unidade de biomassa nas maiores doses, porém estas podem ter reduzido a população dos microrganismos.

$\mathrm{O}$ ametryn atua na inibição do fotossistema II (Silva et al., 2007), podendo ser letal para os microrganismos fotossintetizantes, como algas, cianobactérias, bactérias do enxofre, entre outros microrganismos (Moreira \& Siqueira, 2006). Também os ingredientes inertes das formulações dos herbicidas, como adjuvantes, podem ocasionar efeitos tóxicos à microbiota do solo, tendo em vista a grande quantidade aplicada ao solo (Agrofit, 2008), com maior efeito que o ingrediente ativo, fato esse constatado por Santos et al. (2005) e Massenssini et al. (2008).

Em condições de casa de vegetação, Reis et al. (2008a) observaram que o ametryn causou maiores efeitos negativos na evolução de $\mathrm{C}-\mathrm{CO}_{2}$ de solo rizosférico quando comparado com os herbicidas 2,4-D e trifloxysulfuron-sodium, também utilizados em cana-de-açúcar. Estudos mostraram que o atrazine, também inibidor do fotossistema II, aplicado em campo na cultura do milho, não influenciou a evolução de $\mathrm{C}-\mathrm{CO}_{2}$ do solo (Jakelaitis et al., 2007). 
Nos tratamentos com a mistura de trifloxysulfuron-sodium + ametryn, não houve diferenças entre os tratamentos com duas e oito vezes a dose de referência $(7,315+$ $0,185 \mathrm{mg} \mathrm{dm}^{-3} \mathrm{de}$ solo), em relação à testemunha. Os demais tratamentos apresentaram diferença para evolução diária de $\mathrm{C}-\mathrm{CO}_{2}$ (Figura 3A). Ao aplicar a mistura em quatro vezes a dose de referência, houve menor evolução diária de $\mathrm{C}-\mathrm{CO}_{2}$, comparativamente aos demais tratamentos. Esse efeito pode ser atribuído à redução da biomassa microbiana, devido aos efeitos tóxicos do composto, porém sem causar efeitos negativos de aumento considerável da evolução de $\mathrm{C}-\mathrm{CO}_{2}$ das espécies restantes, como pode ter ocorrido no tratamento com a maior dose. Efeito sinérgico da mistura de herbicidas na atividade da microbiota do solo foram observados por Santos et al. (2005), com aplicação da mistura de fluazifop-p-butil + fomesafen em campo na cultura do feijão.

A evolução de $\mathrm{C}-\mathrm{CO}_{2}$ acumulada, nos tratamentos que envolveram a mistura de trifloxysulfuron-sodium + ametryn, foi maior quando se aplicaram duas, quatro e oito vezes a dose de referência, diferenciando-se da dose 1 e da testemunha sem herbicidas (Figura 3B). As maiores doses ocasionaram elevado estresse microbiano ou também o herbicida pode ter sido letal a parte da

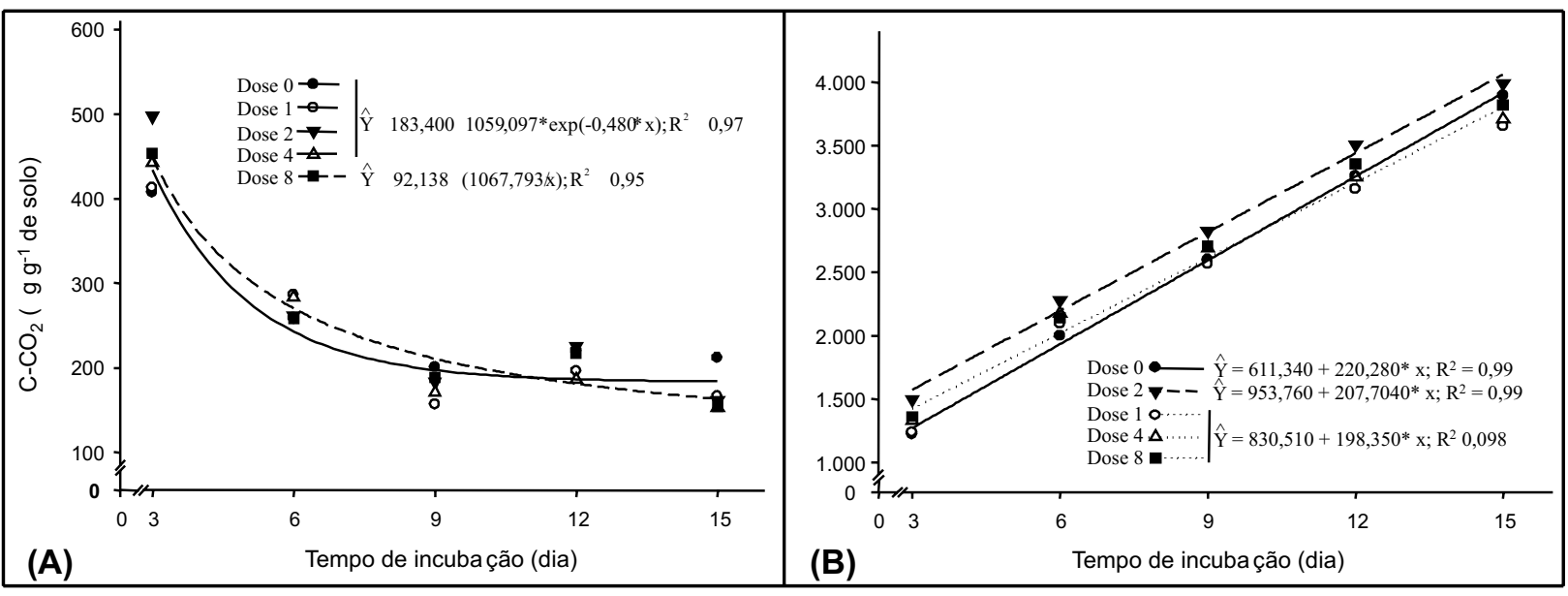

Figura 2 - Evolução diária (A) e acumulada (B) de $\mathrm{CO}_{2}\left(\mathrm{C}_{-} \mathrm{CO}_{2}\right)$ do solo após a incubação, em função da aplicação do herbicida ametryn nas doses de $0,1,2,4$ e 8 vezes a dose de referência (10 $\mathrm{mg} \mathrm{dm}^{-3}$ de solo). Viçosa-MG, 2008.

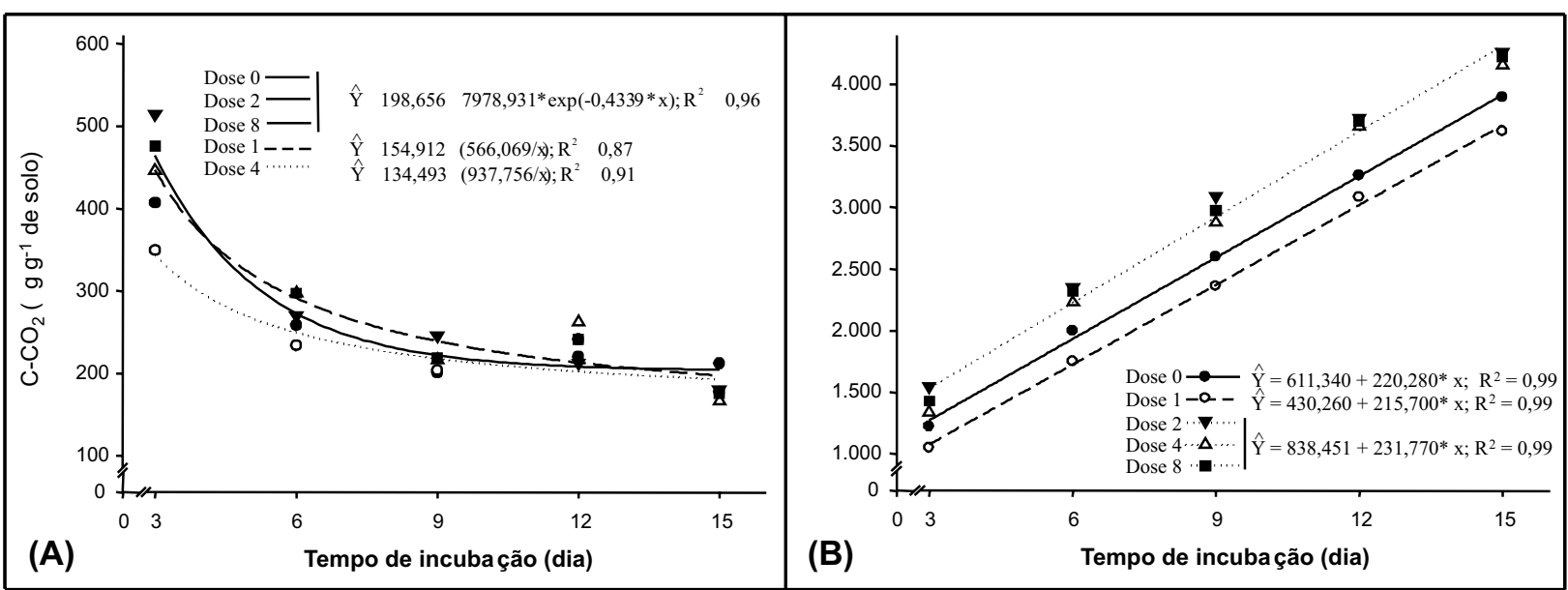

Figura 3 - Evolução diária (A) e acumulada (B) de $\mathrm{CO}_{2}\left(\mathrm{C}_{-}-\mathrm{CO}_{2}\right)$ do solo após a incubação, em função da aplicação do herbicida trifloxysulfuron-sodium + ametryn nas doses de $0,1,2,4$ e 8 vezes a dose de referência $\left(7,315+0,185 \mathrm{mg} \mathrm{dm}^{-3} \mathrm{de} \mathrm{solo}\right)$ Viçosa-MG, 2008 
população microbiana, estimulando assim outras populações insensiveis ao composto, com maior respiração e crescimento, usando as células mortas como fonte de energia (Sakamoto \& Obo, 1994), ou os maiores valores de respiração em função da decomposição dos herbicidas (Moreno et al., 2007).

A dose de referência apresentou menor valor de $\mathrm{C}-\mathrm{CO}_{2}$ acumulado comparativamente à testemunha, podendo isso ser atribuído a efeitos sinérgicos dos herbicidas, reduzindo algumas populações de microrganismos, sem alterar consideravelmente a respiração (estresse) daqueles que permaneceram no ambiente (Figura 3B). A mistura trifloxysulfuron-sodium + ametryn apresentou efeitos semelhantes aos do ametryn em aplicação isolada, promovendo maior taxa de evolução de $\mathrm{C}-\mathrm{CO}_{2}$, quando comparada com o trifloxysulfuron-sodium (Reis et al., 2008a).

O trifloxysulfuron-sodium promoveu redução do CBM nas menores doses; já nas maiores, proporcionou estímulo ao crescimento da população microbiana (Figura 4A). Santos et al. (2005), ao trabalharem com o fluazyfop-p-butil, atribuíram esse comportamento ao estresse e à limitação de crescimento de parte da população microbiana nas menores doses. Com o aumento da dose, esses autores constataram que o herbicida pode ter sido tóxico a parte da população de microrganismos, ocorrendo estímulo de crescimento de microrganismos saprófitas, insensiveis ao herbicida. Parte desse comportamento pode ser atribuída à redução da competição entre os microrganismos do solo, permitindo crescimento de outras populações. Zilli et al. (2007) observaram redução do $\mathrm{CBM}$ em solo com aplicação de imazaquin, herbicida inibidor da enzima ALS, alterando também a composição das espécies que compõem as populações de microrganismos.

$\mathrm{O}$ ametryn influenciou negativamente a biomassa microbiana, com maiores reduções nas maiores doses testadas (Figura 4A). Este herbicida, como já relatado, tem a capacidade de agir sobre a microbiota do solo, em função de seu mecanismo de ação e dos componentes inertes de sua formulação comercial.

A mistura de trifloxysulfuron-sodium + ametryn provocou efeitos intermediários no
CBM, comparativamente aos herbicidas aplicados isoladamente, com redução dessa variável com o aumento da dose (Figura 4A). Resultados semelhantes foram encontrados por Reis et al. (2008a) com aplicações do trifloxysulfuron + ametryn na cana-de-açúcar, em ambiente protegido, proporcionando redução da biomassa microbiana da rizosfera da cultura.

O trifloxysulfuron-sodium provocou comportamento linear decrescente para o $\mathrm{qCO}_{2}$, quando aplicado em diferentes doses, caracterizando maior equilíbrio dos microrganismos do solo, o que significa maior eficiência destes na incorporação de carbono com o aumento da dose (Figura 4B). Esse comportamento pode ser atribuído aos efeitos benéficos a algumas populações microbianas e/ou maléficos a outras, reduzindo algumas populações de microrganismos, ou também estimulando outras populações saprófitas (Santos et al., 2005), com menor competição entre os microrganismos. O ametryn apresentou efeitos negativos para o $\mathrm{qCO}_{2}$, os quais foram maiores com o aumento das doses. Esses resultados representam estresse dos microrganismos do solo, com maior gasto de energia $\left(\mathrm{CO}_{2}\right)$ e menor crescimento da biomassa. O trifloxysulfuron-sodium + ametryn proporcionou redução deste parâmetro até o tratamento que envolveu quatro vezes a dose de referência, apresentando comportamento similar ao do trifloxysulfuron-sodium aplicado isoladamente. No tratamento com oito vezes a dose, houve aumento do $\mathrm{qCO}_{2}$ - comportamento similar ao do ametryn em aplicação isolada. Reis et al. (2008a) não observaram diferenças no $\mathrm{qCO}_{2}$ do solo rizosférico entre os tratamentos com aplicação da mistura trifloxysulfuronsodium + ametryn e o ametryn aplicado em cana-de-açúcar.

O trifloxysulfuron-sodium promoveu estímulo à solubilização de fosfato inorgânico, com maiores efeitos com elevação das doses, tendendo a estabilizar nas maiores doses testadas (Figura 5A). Esse comportamento pode ser atribuído ao aumento do CBM ou à seleção de microrganismos com maior eficiência na solubilização. Griffiths et al. (2008) observaram mudança na constituição da comunidade de microrganismos após aplicação de glufosinato de amônio. No entanto, acredita-se que as 


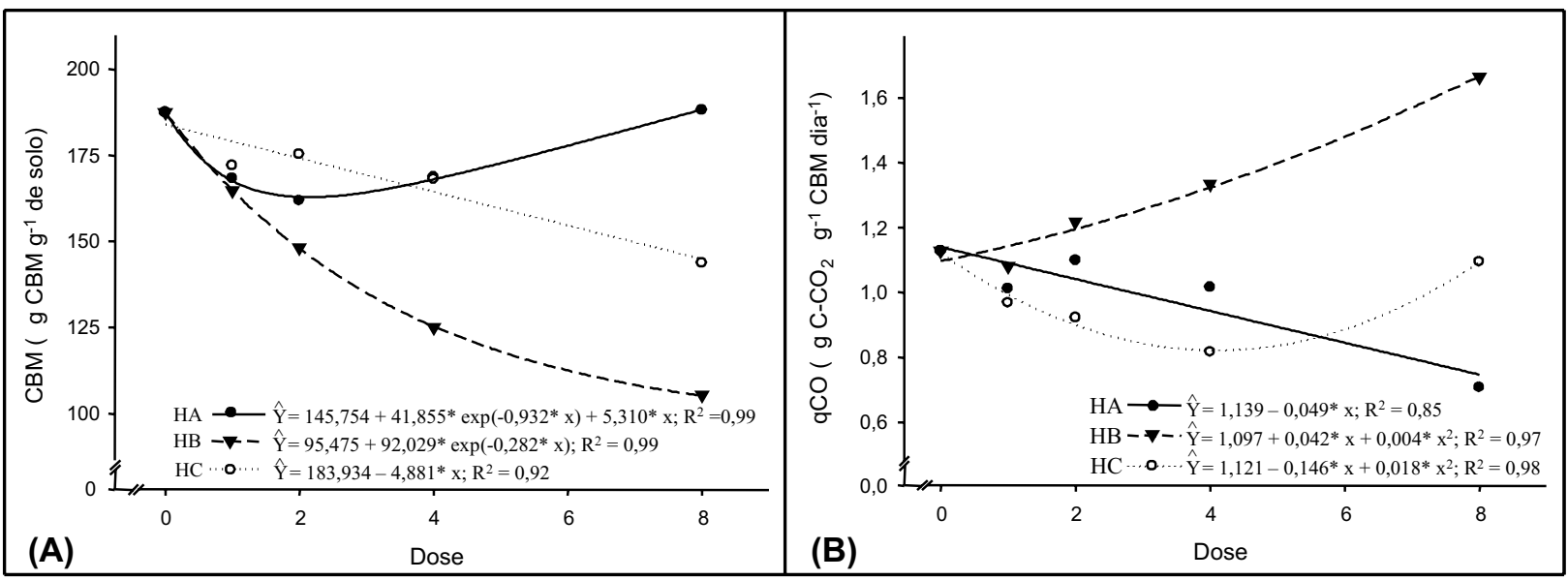

Figura 4 - Carbono da biomassa microbiana - $\mathrm{CBM}(\mathrm{A})$ e quociente metabólico - $\mathrm{qCO}_{2}(\mathrm{~B})$ do solo, 15 dias após a incubação, em função da aplicação dos herbicidas trifloxysulfuron-sodium (HA), ametryn (HB) e trifloxysulfuron-sodium + ametryn (HC) nas doses de 0, 1, 2, 4 e 8 vezes a dose de referência de cada herbicida. Viçosa-MG, 2008.

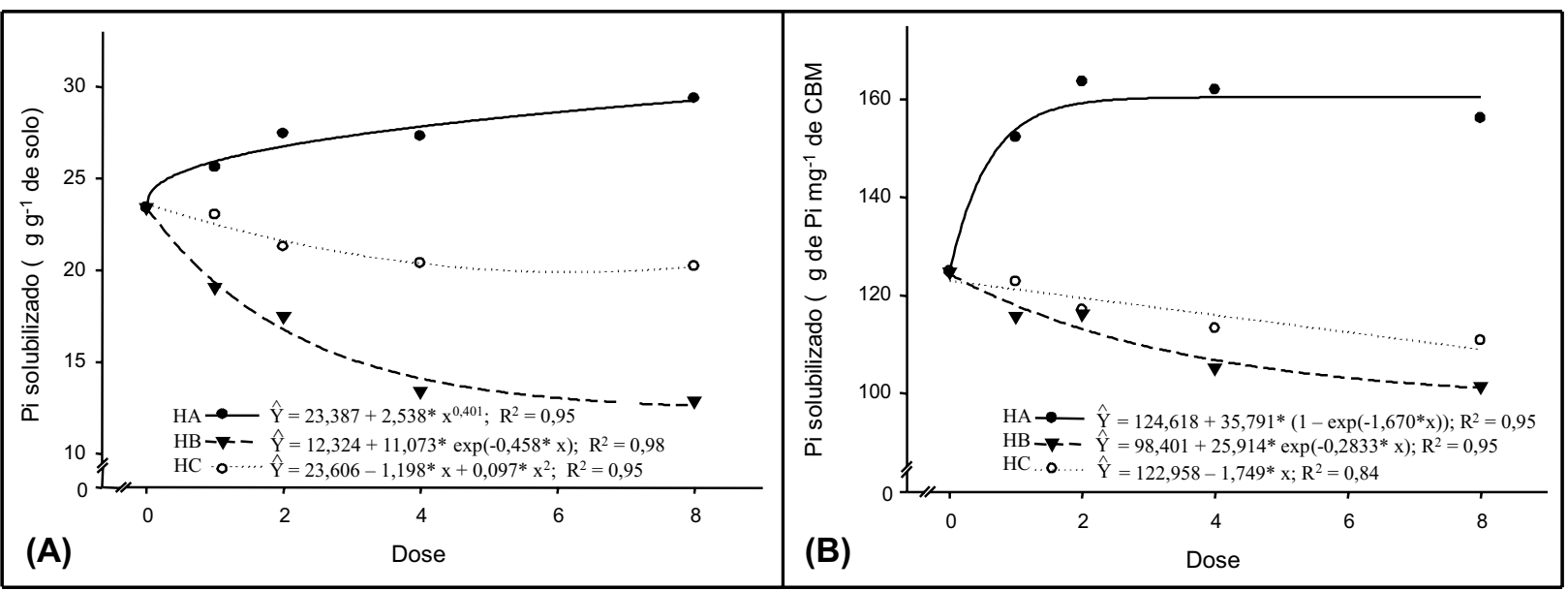

Figura 5 - Solubilização potencial (A) e solubilização potencial relativa (B) de fósforo inorgânico $\left(\mathrm{Ca}_{3}\left(\mathrm{PO}_{4}\right)_{2}\right)$ pelos microrganismos solubilizadores de fósforo inorgânico do solo, 15 dias após a aplicação dos herbicidas trifloxysulfuron-sodium (HA), ametryn $(\mathrm{HB})$ e trifloxysulfuron-sodium + ametryn (HC) nas doses de $0,1,2,4$ e 8 vezes a dose de referência de cada herbicida. Viçosa-MG, 2008

maiores taxas de solubilização se devam ao estímulo do herbicida à liberação de ácidos orgânicos pelos microrganismos do solo (Reis et al., 2008b). Os ácidos orgânicos liberados pelos microrganismos são considerados o principal mecanismo para a solubilização de fosfatos inorgânicos do solo (Moreira \& Siqueira, 2006).

$\mathrm{O}$ ametryn proporcionou maior redução no potencial de solubilização de fosfato inorgânico, sendo os efeitos maiores com o aumento das doses, tendendo à estabilização nas maiores doses (Figura 5A). Efeitos negativos do ametryn no potencial de solubilização de fósforo inorgânico foram relatados por Reis et al. (2008b).

O potencial de solubilização de fosfato inorgânico foi influenciado pelas doses de trifloxysulfuron-sodium + ametryn, sendo os maiores efeitos negativos nas maiores doses. A mistura apresentou efeitos intermediários em relação aos herbicidas aplicados isoladamente, evidenciando efeito aditivo entre os herbicidas (Figura 5A).

Quanto à solubilização relativa de fosfato inorgânico, o trifloxysulfuron-sodium proporcionou estímulo para essa variável, reforçando a hipótese de seleção de espécies com maior 
potencial de solubilização, ou estímulo dessas populações na produção de ácidos orgânicos (Reis et al., 2008b). O trifloxysulfuron-sodium + ametryn apresentou efeitos negativos e mais pronunciados com o aumento da dose, com comportamento semelhante ao do ametryn quando aplicado isoladamente.

Conclui-se que a evolução de $\mathrm{C}-\mathrm{CO}_{2}$ é influenciada pelos herbicidas e doses, ocorrendo os maiores efeitos logo após a aplicação e nas maiores doses. $\mathrm{O} \mathrm{CBM}$ e o $\mathrm{qCO}_{2}$ foram influenciados negativamente pelos herbicidas ametryn e trifloxysulfuron-sodium + ametryn, com maiores efeitos com o aumento da dose. $\mathrm{O}$ trifloxysulfuron-sodium ocasionou a redução do CBM nas menores doses e o aumento nas maiores, com diminuição do $\mathrm{qCO}_{2}$ proporcionalmente ao acréscimo das doses. O ametryn e o trifloxysulfuron-sodium + ametryn provocaram redução no potencial e potencial relativo de solubilização de fosfato, enquanto o trifloxysulfuron-sodium estimulou a solubilização.

\section{AGRADECIMENTOS}

Ao Conselho Nacional de Desenvolvimento Científico e Tecnológico (CNPq), pelas concessões de bolsas e pelo apoio financeiro para a realização da pesquisa.

\section{LITERATURA CITADA}

AGROFIT. Sistema de Agrotóxicos Fitossanitários. Disponível em: $<$ http://extranet.agricultura.gov.br/agrofit $>$. Acesso em: 21 de dez. de 2008.

BARROSO, C. B.; NAHAS, E. The status of soil phosphate fractions and the ability of fungi to dissolve hardly soluble phosphates. Appl. Soil Ecol., v. 29, n. 1, p. 73-83, 2005.

BOTTOMLEY, P. J. Microbial ecology. In: SYLVIA, D. M. et al. Principles and applications of soil microbiology. 2.ed. New Jersey: Upper Saddle River, 2005. p. 463-488.

BRAGA, J. M.; DEFELIPO, B. V. Determinação espectrofotométrica de fósforo em extratos de solos e plantas. R. Ceres, v. 21, n. 113, p. 73-85, 1974.

BROOKES, P. C. The use of microbial parameters in monitoring soil. The use of microbial parameters in monitoring soil pollution by heavy-metals. Biol. Fert. Soils, v. 19 , n. 2, p. $269-279,1995$
CHAER, M. C.; TÓTOLA, M.R. Impacto do manejo de resíduos orgânicos durante a reforma de plantios de eucalipto sobre indicadores de qualidade do solo. R. Bras. Ci. Solo, v. 31, n. 6, p. 1381-1396, 2007.

CHRISTOFFOLETI, P. J. et al. Carfentrazone-ethyl aplicado em pós-emergência para o controle de Ipomoea spp. e Commelina benghalensis na cultura da cana-de-açúcar. Planta Daninha, v. 24, n. 1, p. 83-90, 2006.

COSTA, M. A.; MONTEIRO, R. T. R.; TORNISIELO, V. L. Influência da adição de palha de cana-de-açúcar na degradação de 14C-ametrina em solo areia quartzosa. Sci. Agric., v. 54, n. 3, p. 117-122, 1997.

DAS, A. C.; DEBNATH, A.; MUKHERJEE, D. Effect of the herbicides oxadiazon and oxyfluorfen on phosphates solubilizing microorganisms and their persistence in rice fields. Chemosphere, v. 53, n. 2, p. 217-221, 2003.

FRANZLUEBBERS, A. S. Integrated crop-livestock systems in the Southeastern USA. Agron. J., v. 99, n. 3, p. 361-372, 2007.

FREITAS, J. R.; BANERJEE, M. R.; GERMIDA, J. J. Phosphate solubilizing rhizobacteria enhance the growth and yield but not uptake of canola (Brassica napus L.). Biol. Fert. Soils, v. 24, n. 4, p. 358-364, 1997.

GRAYSTON, S. J.; VAUGHAN, D.; JONES, D. Rhizosphere carbon flow in trees, in comparison with annual plants: The importance of root exudation and its impact on microbial activity and nutrient availability. Appl. Soil Ecol., v. 5, n. 1, p. $29-56,1996$.

GRIFFITHS. B. S. et al. Soil microbial and faunal responses to herbicide tolerant maize and herbicide in two soils. Plant Soil, v. 308, n. 1, p. 93-103, 2008.

GYANESHWAR, P. et al. Role of soil microorganisms in improving P nutrition of plants. Plant Soil, v. 245, n. 1, p. 83-93, 2002

\section{INSTITUTO BRASILEIRO DE GEOGRAFIA E} ESTATÍSTICA - IBGE. 2008. Disponível em: <http:// www.ibge.gov.br/estatistica/indicadores/>. Acesso em: $10 \mathrm{dez}$. 2008.

ISLAM, K. R.; WEIL, R. R. Microwave irradiation of soil for routine measurement of microbial biomass carbon. Biol. Fert. Soils, v. 27, n. 4, p. 408-416, 1998.

JAKELAITIS, A. et al. Atividade microbiana e produção de milho (Zea mays) e de Brachiaria brizantha sob diferentes métodos de controle de plantas daninhas. Planta Daninha, v. 25, n. 1, p. $71-78,2007$.

KUVA, M. A. et al. Periodos de interferência das plantas daninhas na cultura da cana-de-açúcar. III - capim-braquiária (Brachiaria decumbens) e capim-colonião (Panicum maximum). Planta Daninha, v. 21, n. 1, p. 37-44, 2003 
LEITA, L. et al. Bioavalability and effects of heavy-metals on soil microbial biomass survival during laboratory incubation. Biol. Fert. Soils, v. 19, n. 1 p. 103-108, 1995.

MASSENSSINI, A. M. et al. Atividade de isolados bacterianos solubilizadores de fosfato na presença de formulações comerciais de glyphosate. Planta Daninha, v. 26, n. 4 , p. $815-823,2008$

MORENO, J. L. et al. Effects of atrazine on microbial activity in semiarid soil. Appl. Soil Ecol., v. 35, n. 1, p. 120-127, 2007.

MOREIRA, F. M. S.; SIQUEIRA, J. O. Microbiologia e bioquímica do solo. 2.ed. Lavras: Universidade Federal de Lavras, 2006. 729 p.

NAUTIYAL, C. S. An efficient microbiological growth medium for screening phosphate solubilizing microorganisms FEMS Microbiol. Letters, v. 170, n. 1, p. 265-270, 1999.

NAUTIYAL, C. S. et al. Stress induced phosphate solubilization in bacteria isolated from alkaline soils. FEMS Microbiol Lett, v. 182, n. 2, p. 291-296, 2000.

NEGRISOLI, E. et al. Seletividade de herbicidas aplicados em pré-emergência na cultura da cana-de-açúcar tratada com nematicidas. Planta Daninha, v. 22, n. 4, p. 567-575, 2004.

NOVAIS, R. F.; SMYTH, T. J. (Eds.). Fósforo em solo e planta em condições tropicais. Viçosa, MG: Universidade Federal de Viçosa, 1999. 399 p.

PEREIRA, J. L et al. Effects of glyphosate and endosulfan on soil microorganisms in soybean crop. Planta Daninha, v. 26, n. 4 , p. 825-830, 2008.

PROCÓPIO, S. O. et al. Manejo de plantas daninhas na cultura da cana-de-açúcar. Viçosa-MG: Universidade Federal de Viçosa, 2003. 150 p.

REGAZZI, A. J. Teste para verificar igualdade de modelos de regressão e a igualdade de alguns parâmetros num modelo poligonal ortogonal. R. Ceres, v. 40, n. 2, p. 176-195, 1993.

REGAZZI, A. J.; SILVA, C. H. O. Teste para verificar a igualdade de parâmetros e a identidade de modelos de regressão não-linear. I dados no delineamento inteiramente casualizado. R. Mat. Estat., v. 22, n. 3, p. 33-45, 2004.

REIS JR., R. A.; MONNERAT, P. H. Diagnose nutricional da cana-de-açúcar em Campos dos Goytacazes (RJ). R. Bras. Ci. Solo, v. 26, n. 3, p. 367-372, 2002
REIS, M. R. et al. Atividade microbiana em solo cultivado com cana-de-açúcar após aplicação de herbicidas. Planta Daninha, v. 26, n. 2, p. 323-331, 2008a.

REIS, M. R. et al. Ação de herbicidas sobre microrganismos solubilizadores de fosfato inorgânico em solo rizosférico de cana-de-açúcar. Planta Daninha, v. 26, n. 2, p. 333-341, $2008 b$.

SANTOS, J. B. et al. Atividade microbiana do solo após aplicação de herbicidas em sistemas de plantio direto e convencional. Planta Daninha, v. 23, n. 4, p. 683-691, 2005.

SAKAMOTO, K.; OBO, Y. Effects of fungal to bacterial ratio on the relationship between $\mathrm{CO}_{2}$ evolution and total soil microbial biomass. Biol. Fert. Soils, v. 17, n. 1, p. 39-44, 1994.

SILVA, A. A. et al. Herbicidas: classificação e mecanismo de ação. In: SILVA, A. A.; SILVA, J. F. (Eds.). Tópicos em manejo de plantas daninhas. Viçosa, MG: Universidade Federal de Viçosa, 2007. p. 83-148.

SOUZA, E. D. et al. Carbono orgânico e fósforo microbiano em sistema de integração agricultura-pecuária submetido a diferentes intensidades de pastejo em plantio direto. R. Bras. Ci.Solo, v. 32, n. 3, p. 1273-1282, 2008.

SYNGENTA. Syngenta Foundation. 2006. Disponível em: $<$ http://www. syngenta. com/products/services/krismat>. Acesso em: 30 de out. de 2008

TÓTOLA, M. R.; CHAER, G. M. Microrganismos e processos microbiológicos como indicadores da qualidade dos solos. In: ALVAREZ V., V. H. et al. (Eds.). Tópicos em Ciência do solo. 2.ed. Viçosa, MG: Sociedade Brasileira de Ciência do Solo, 2002. p. 195-276.

VANCE, E. D.; BROOKES, P. C.; JENKINSON, D. S. An extraction method for measuring soil microbial biomass C. Soil Biol. Biochem., v. 19, n. 6, p. 703-707, 1987.

VIVIAN, R. et al. Persistência de sulfentrazone em Argissolo Vermelho-Amarelo cultivado com cana-de-açúcar.

Planta Daninha, v. 24, n. 4, p. 471-480, 2006.

ZABALOY, M. C.; GARLAND, J. L.; GÓMEZ, M. A. An integrated approach to evaluate the impacts of the herbicides glyphosate, 2,4-D and metsulfuron-methyl on soil microbial communities in the Pampas region, Argentina. Appl. Soil Ecol., v. 40, n. 1, p. 1-12, 2008.

ZILLI, J. E. et al. População microbiana em solo cultivado com soja e tratado com diferentes herbicidas em área de cerrado no Estado de Roraima. Acta Amaz., v. 37, n. 2, p. 201-212, 2007 